\title{
Effects of Strobilanthes crispus juice on wound healing and antioxidant enzymes in normal and streptozotocin-induced diabetic rats.
}

\begin{abstract}
The objective of this study is to determine the effect of Strobilanthes crispus Juice (SCJ) on wound healing and antioxidative enzymes activity in normal and streptozotocin-induced rats. A total of 48 male albino Sprague dawley rats, weight 150-200 g were used. The rats were divided into 8 groups with 6 rats in each group. The healing of $2 \mathrm{~cm}$ linear incisions created on the back of each rat was monitored by measuring the length of the wounds daily. The result showed a significant increase $(\mathrm{p}<0.05)$ in the percentage of wound healing at day 3 and 7 in the treated group especially treated with $140 \mathrm{mg} \mathrm{kg}-1 \mathrm{~b} . \mathrm{wt}$. of S. crispus juice in diabetic and normal rats compared with the control. Strobilanthes crispus juice increased significantly $\mathrm{p}(<0.05)$ of glutathione peroxidase (GPx) and superoxide dismutase (SOD) activity in treated group in diabetic rats. Significant correlation was found between wound healing, GPx and SOD enzymes. In conclusion, S. crispus juice enhanced wound healing in normal and diabetic rats.
\end{abstract}

Keyword: Strobilanthes crispus juice; Wound healing; Glutathione peroxidase; Superoxide dismutase. 